\title{
Mining initiative on ground support and equipment: 12 years of accomplishments
}

\author{
G Swan Rock Mechanics and Mine Design, Canada \\ J Hedlin Rock Tech Centre AB, Sweden
}

\begin{abstract}
Ground support and its associated equipment have a significant impact on safety and productivity in both mining and construction. Since 2007, the industry-funded Rock Tech Centre's Mining Initiative on Ground Support Systems and Equipment (MIGS) consortium has initiated and managed a variety of projects representing the collective and non-competitive interests of the global mining and service industry. From the beginning, using an agreed program of projects and seminars, the goal has been to obtain a beneficial advance in the capability of ground support and its installation equipment technology by:

- Promoting a rationalised approach to ground support system design and testing.

- Seeking a standardisation of equipment functionality and productivity improvements.

- Evaluating innovative methods of monitoring support systems and their interaction with the rock mass.

- Seeking the development of rock support with greater dynamic capacity to deform for deep mining applications.

- Exchanging technical and operational information.
\end{abstract}

This paper elaborates on the above goals and summarises some of the major achievements and key conclusions of a 12-year program of 25 work packages.

Keywords: ground support design, testing rigs, bolt monitoring, equipment productivity improvement

\section{Introduction}

As more mining operations take on the challenge of exploiting deeper orebodies, improvements in ground support technology and methodology are of increasing importance to the widely sought goals of higher productivity, lower costs and increased safety. In the past the means of achieving such improvements relied heavily upon in-house technology groups, supported by universities and governmental research agencies, but today key advances are increasingly being driven by industry-wide consortia-funded initiatives. The greater financial leverage and the sole focus on short-term, non-competitive, readily applicable value-added deliverables have served to justify the existence of such consortia.

In the case of the Rock Tech Centre's Mining Initiative on Ground Support Systems and Equipment (MIGS) consortium founded in 2007, the measure of its success can be judged by the accompanying review of its technical activities and summarised output completed over three consecutive four-year programs (MIGS I, II and III). First, a description of how MIGS program of activities is managed, decided and executed will be presented.

Since its inception, the MIGS consortium membership has comprised Swedish and international mining companies together with ground support element and equipment suppliers. Members join on the understanding that all the consortium's activities are chosen in the interests of their collective and non-competitive interests. Experience has shown that, on this basis and through a carefully managed process of topic selection at the beginning of each of the 3-4 year programs, a variety of short-term 
(typically 3-18 months) state-of-the-art studies are agreed upon, together with certain seminar topics and the occasional longer-term (3-4 year) milestone-triggered project. Essentially, five distinct subject areas have been addressed in this way: ground support design, ground support testing, ground support equipment, ground support monitoring, and corrosion of ground support. Each study or work package is assigned a technical project leader who is recruited on a consultant basis from inside or outside the consortium and is directly responsible for the project's deliverable/s. This leader is supported by the consortium's technical program manager and a working or reference group comprising those members who have a direct interest in the topic. The progress and deliverable(s) from each work package are reviewed and documented at a 1-2 day workshop held twice annually at a convenient location.

The following provides a summary of highlights from 12 years of the MIGS consortium's 25 work packages, grouped according to the above five subject areas.

\section{Ground support design: bolts and liners}

Twelve of the 25 MIGS work packages fall under the category of ground support design (bolts and liners), indicating a high level of interest in and a need to know more about this area by mining companies and suppliers represented in the consortium. Work package subjects covered a wide range of topics, from ductile performing bolts and liners and bolt shear capacity requirements and functionality to state-of-the-art reviews of new product types and ground support designs for rockbursting conditions. A longer-term in-depth study was also initiated evaluating rock support element response and effectiveness under dynamic rockbursting conditions. This particular study was initiated after a review of rockburst support case histories found that, based upon reports received from various burst-prone mines, lessons learned from observations of support damage proved frustratingly inconclusive.

\subsection{State of the art: ductile ground support systems and elements}

A comprehensive state-of-the-art (SOTA) work package on ductile ground support systems and elements was completed in 2008 based upon a literature review together with interviews with 24 experts from six countries (Li 2008) and visits to 10 mines, one civil tunnel, one bolt supplier and three mining research institutions. Follow-up and subsequent studies focused on the conceptual requirements (Stille et al. 2009), laboratory tests and underground trials that have attempted to achieve ductile surface support from both shotcrete and polymeric materials (thin spray-on liners). In addition, a further SOTA work package was completed in 2015, which reported, in part, on new developments in ductile ground support systems and elements (Hadjigeorgiou 2015).

After reviewing all these studies, the following summary conclusions have been made, which are applicable to mines subject to high stress/deformation of brittle or soft squeezing ground:

1. Given the current ongoing limitations in the capacity of ductile support elements, a three-tier or layered system is the ultimate and preferred philosophy, namely: (a) surface liner for retention; (b) short bolts for reinforcement and holding; and (c) longer, more-ductile cable bolts for securing the reinforced zone to more competent rock.

2. In the case of shotcrete liners, a plain concrete matrix has a very limiting strain capacity of $\sim 0.35 \%$ compared with a so-called strain hardening cementitious composite with $\sim 3.5 \%$. In addition, because concrete is a strain-rate sensitive material, comparisons of static and dynamic toughness show significant differences (Utsi et al. 2009).

3. In the case of thin spray-on liners (TSLS), given the range of specifications needed to satisfy normal, rockbursting and strongly deforming ground conditions, results on a variety of different polymeric materials in numerous underground trials and laboratory tests strongly suggest that no one TSL product will suffice (Swan \& Hadjigeorgiou 2010). TSLs have been the subject of experimental research and have been under development for well over two decades, and yet their routine in-cycle application as a ground support component together with rockbolts in 
mining has yet to be realised. While the explanation for this is certainly technical (e.g. Figure 1), it is also clear that proving and communicating the operational requirements as well as the economic case, for why a mine should change from a mesh and/or shotcrete liner to a TSL, is not a trivial matter. Evidence must be obtained, presented and communicated effectively, that is both obvious and compelling.

4. The 2015 SOTA confirmed that certain new types of ductile ground support elements have emerged since 2008, as shown in Table 1 and Table 2 at various stages of development. To provide a means of comparison, a classification system was devised as follows:

a. Class A, internal development-conceptual work/proof of concept study.

b. Class B, tests performed at independent facilities-prototype available for testing under controlled dynamic/static loads.

c. Class C, in situ demonstrations, with some/limited in situ testing trials.

d. Class D, element has become part of a ground support standard at one or more mine sites.

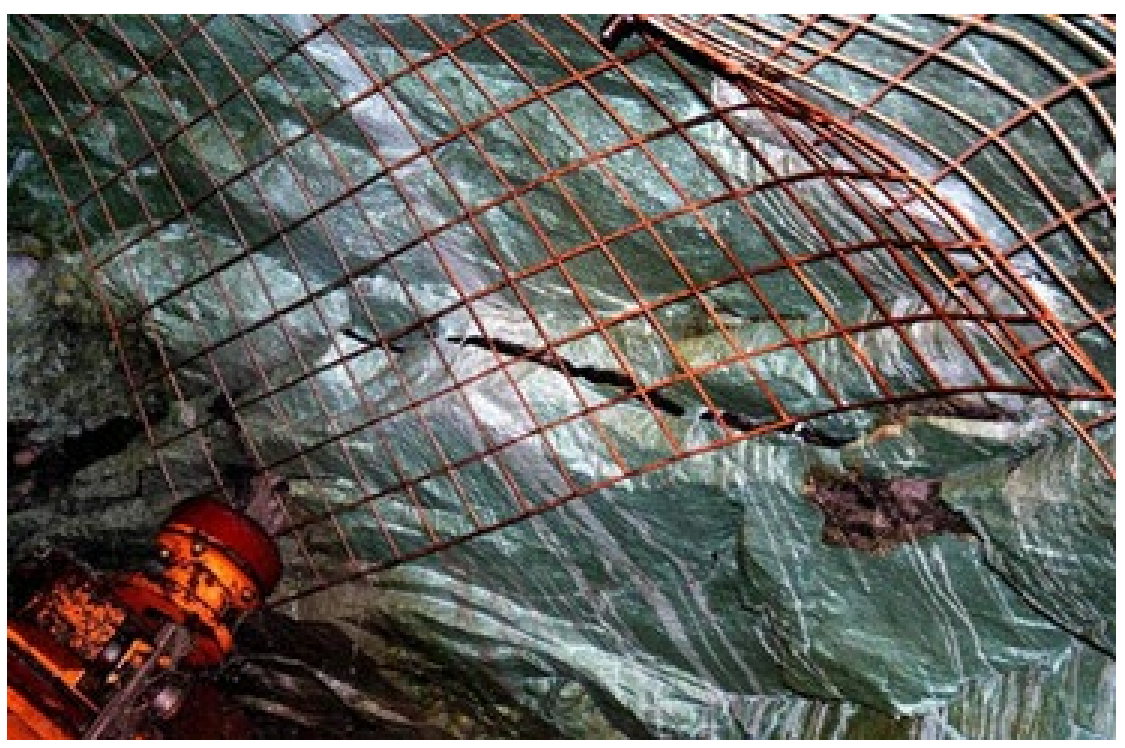

Figure 1 Example of a tearing mode of TSL failure observed while installing bolts in loose ground during an underground field trial (Swan \& Hadjigeorgiou 2010)

Table 1 List of new ductile bolts and their stage of development as of December 2014 (Hadjigeorgiou 2015)

\begin{tabular}{ll}
\hline Reinforcement elements & Classification of stage of development \\
\hline D-bolt & Class D \\
Roofex bolt & Class C \\
Mechanical Dynamic bolt & Class D \\
Dynatork bolt & Class B \\
Yield-Lok bolt & Class D \\
NMP Dynamic Expandable rockbolt & Class B \\
Modified cone bolt, 33 mm diameter & Class D \\
Indented PC strand & Class D \\
\hline
\end{tabular}


Table 2 List of new surface support elements and their stage of development as of December 2014 (Hadjigeorgiou 2015)

\begin{tabular}{ll}
\hline \multicolumn{1}{c}{ Surface support } & Classification of stage of development \\
\hline \multicolumn{2}{c}{ Mesh } \\
\hline High Energy Absorption mesh & Class C \\
MINAX ${ }^{\circledR} /$ TECCO $^{\circledR}$ high-tensile steel wire mesh & Class C \\
FlexKnot (knotted wire mesh) & Class C \\
MFI 3500 mesh & Class D \\
MTI1200 and MTI5000 and MFI-3500-100-NR & Class B \\
and MFI3500-75-NR & Class D \\
Mesh Module (mesh strap) & Class C \\
Dynamic Screen & Thin spray-on liners \\
\hline & Class C \\
\hline RockWeb (spray-on plastics) & Class C \\
3MTM polymeric composite membrane & Class B \\
TamCrete SSL (structural support liner) & \\
\hline
\end{tabular}

In summary, it appears that while shotcrete has made some gradual step changes in ductile performance, this does not warrant it being called a new support element. Conversely, there are new mesh products that have an increased range of capacity, energy absorption and deformation. Finally, TSLs continue to fall short in making the transition to being an accepted component in any ground support standard.

\subsection{Ground support requirements and function}

This study (Bäckblom 2010) was motivated by an aspiration to harmonise and rationalise the design process for bolt types and requirements across a spectrum of mines and ground conditions, with a view to simplifying and standardising the various types of ground support installation equipment. In essence, it sought to answer the somewhat vexing question: Is the wide variety of bolt and mesh types, lengths, plates, nuts et cetera necessary?

The study began with the preparation and distribution of a series of benchmarking questions to five mines that sought information on (a) the design process used to specify their bolt and liner requirements to suppliers and (b) their respective installation quality assurance procedures including long-term monitoring programs. Compilations of the various responses clearly showed that while there was some common ground between companies, many factors influence the final choice of support design, even when using an objective design process such as illustrated in Figure 2. Faced with this dilemma, the study concluded that some degree of rationalisation could at least be achieved by preparing and adopting a set of practical guidelines for ground support design, given (a) squeezing ground conditions and (b) burst-prone conditions with dynamic loads. 


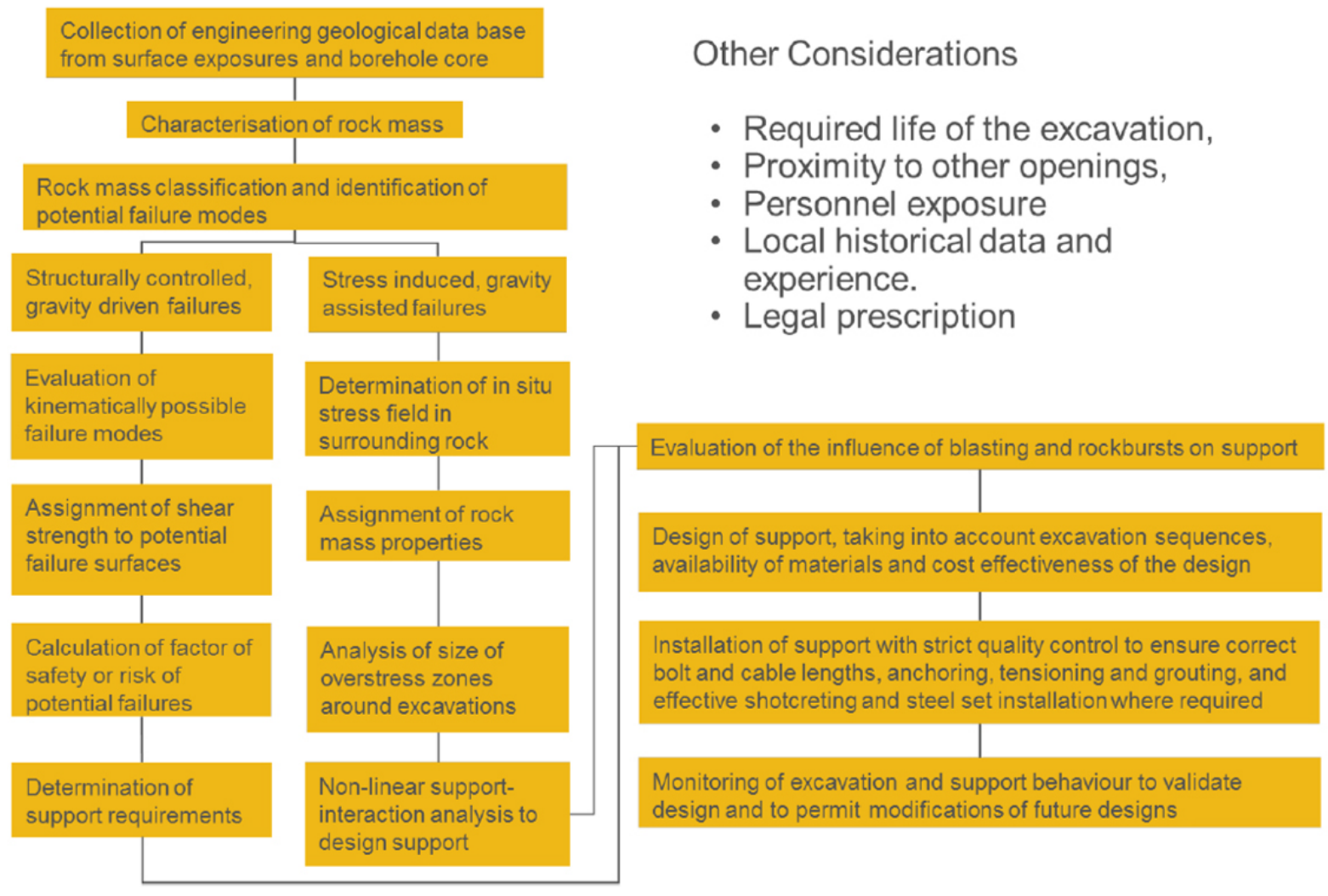

Figure 2 Overview of best-practice ground support design process for support type selection (after Bäckblom 2010)

\subsection{Lessons learned from ground support rockburst damage}

This study began with a careful examination of observational data from nine rockburst/seismic damage case histories from both Canadian and Swedish mine operations across a spectrum of mining methods, rock types, rock structures, depths and ground support systems, with a view to extracting common trends in a lessons-learned exercise. As the study proceeded, while some qualitative statements regarding trends did emerge (Swan 2012) as presented in Table 3, the limitations of the observational data sets and of the existing methods available to evaluate them made it unfeasible to form any practically significant and quantifiable lessons learned.

To address the first of these limitations, a critical SOTA review of regulatory reporting protocols was conducted, as required by the responsible government ministries of Canada and Australia (Andersson 2012). Unfortunately, these reports can only provide, at best, a high-level assessment of what occurred and the nature of the possible mechanism(s); it was never intended that they be prefaced with a thorough forensic data-gathering exercise. Concerning the second limitation, there are currently three approaches available for dynamic support system design: mechanistic, numerical and empirical. Of these, the most commonly used is empirical, the argument being that the results uniquely account for the 'variability and uncertainty impacting the selection' (and design, presumably) of an effective support system (Mikula 2012a). However, a review of existing empirical methods used in Australia and Canada to evaluate rockburst support performance has confirmed that poorly constrained data sets of the variables involved at the time of a rockburst occurrence-the support system's reserve toughness capacity, the stored strain energy in the participating rock mass, site-specific peak particle velocity records of any interacting/reflecting stress waves et cetera-all point to the inevitable shortcomings of such an approach. This also appears to be the conclusion obtained from recent attempts reported in the literature, for example, Mikula (2012b), Heal et al. (2006) and Morissette et al. (2011). 
Table 3 Lessons-learned topics, based upon nine reported cases of damaging rockbursts from Canadian and Swedish mines, ranked according to MIGS II membership level of interest (Swan 2012)

\begin{tabular}{ll}
\hline Rank & Topic \\
\hline \multirow{3}{*}{$90 \%$} & Support toughness is critical, not strength or stiffness \\
& Bolt pattern is critical, not coverage (always true) \\
& Rebar redundant in areas of high deformation: D-bolt has replacement capacity \\
& Hard to assess unused capacity of system: need reliable diagnostics \\
& Rockburst mechanism most commonly mixed mode: strainburst/fault slip/pillar \\
& burst/rock mass shear/gravity fall \\
& Just-in-time development in stress shadowed/yielded rock conditions \\
& Need for autonomous robotics in high-risk areas \\
& Need more global deformation monitoring devices: too much reliance on seismic \\
& monitoring system \\
& Need to complement seismic with a global convergence monitoring system: vertical \\
arrays of passive pressure meters in backfilled primary stopes?
\end{tabular}

In the light of the above it seemed reasonable to defer the original objective of this work package until an alternative, more objective approach became available, which in turn could justify and drive the need for a mine to collect better constrained data sets. In the meantime, there appeared to be value in attempting to evaluate the dynamics of a ground support system's effectiveness and sensitivity to a well-specified set of loading conditions using a numerical model (Figure 3). In short, the relatively simple but mechanistically realistic ideas of Wagner (1982) and Hedley (1992) would be revisited using well-calibrated numerical models and a multiphased approach, the objective being to develop a set of dynamic support design guidelines together with a methodology for assessing a true scale of support effectiveness in burst-prone mines.

Phase 1 of meeting this objective involved developing a rock support response during a fault slip seismic event numerically that incorporated the following:

- Rock damage processes-rock fracturing, displacement and ejection.

- Different loading and its superposition on a specific excavation (excavating a drift, mining in the vicinity and seismic loading).

- Wave amplification around fracture zone interface and free surface.

- Wave attenuation through fracture zone and jointed rock mass.

- Frequency-dependent dynamic vibration (not only single peak values, e.g. PPA or PPV).

- Different bolt and liner functions: fully grouted rebar, Swellex, SplitSet, D-bolt and fibre-reinforced shotcrete.

Phase 2 investigated a suitable method of evaluating support effectiveness, knowing that support resistance (defined as the support load carried by the support component per square metre) will begin to drop as surface deformation increases and the support system loses its loading/deformation capacity. At the same time, the depth of the fractured zone will not increase because the broken support system cannot transfer more load/energy to the surrounding rock. 
Phase 3 calibrated the numerical model and conducted a parameter sensitivity analysis using a seismic event and observed ground/support damage data from one well-instrumented Swedish mine site. It required almost two years (2015-2017) to acquire this data.
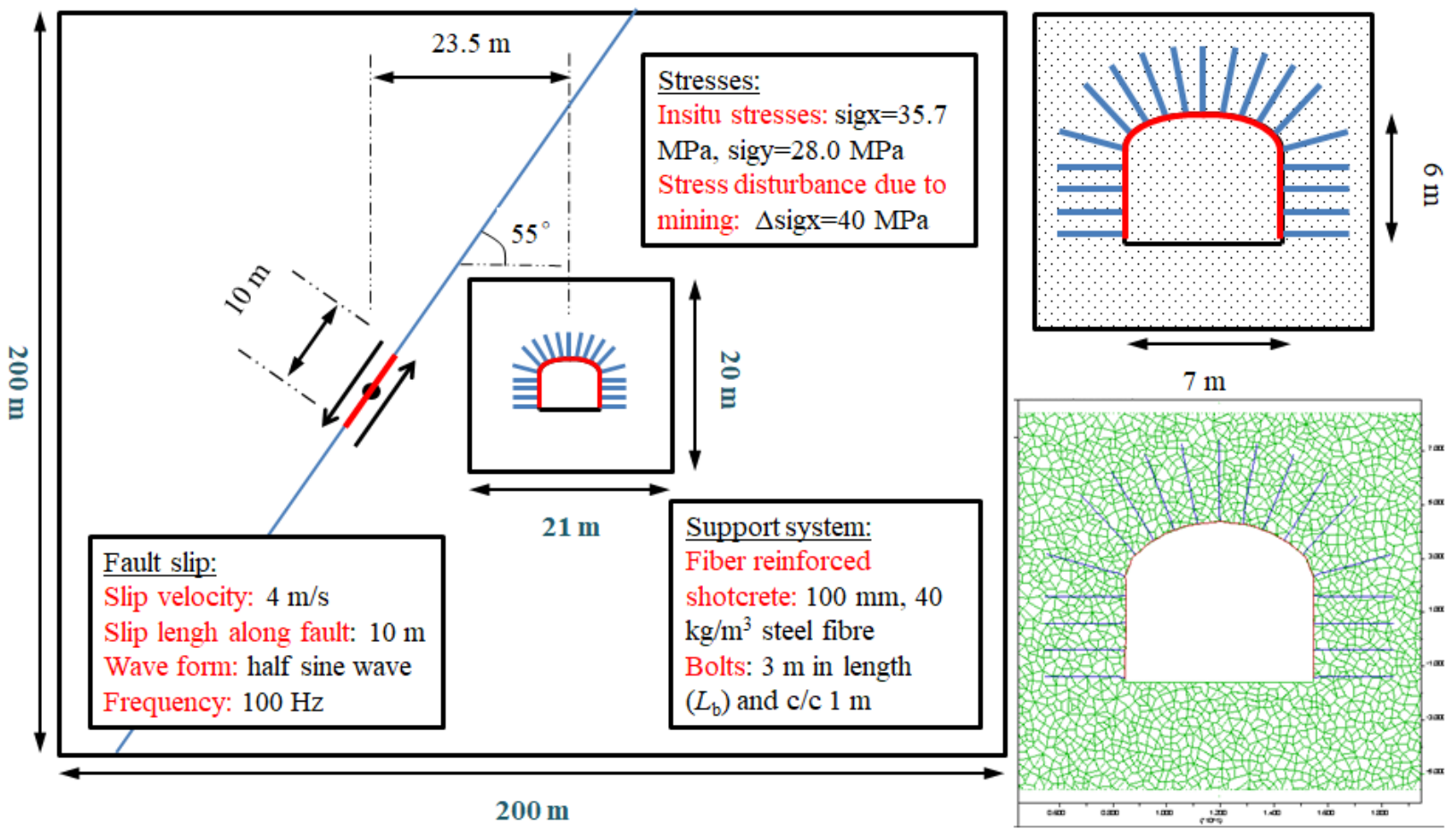

Figure 3 Two-dimensional model of a fault slip event in proximity to a tunnel that has been used to evaluate the performance of support under realistic conditions of rock dynamics (Zhang 2019; Zhang et al. 2015)

Phase 4 , the final phase, used the results from Phase 3 to obtain ideas on how to better design rockburst-resistant support systems and recommendations with regard to defining a true scale of support effectiveness under dynamic loading conditions.

While the stated deliverables from this work package are yet to be finalised, the numerical results from studying wave amplification given a fractured zone at the boundary of a supported excavation have been shown to be significant, depending upon the wave frequency, fracture stiffness, fracture spacing and extent of the fracture zone (Zhang et al. 2015).

\section{Ground support testing: methods and applicability}

Over the course of 12 years, the topic of ground support testing (methods and applicability) has been revisited several times by MIGS using SOTA studies, always with the expectation of finding some preferred, standardised testing procedures for small-scale specification testing and/or large-scale performance testing of ground support components (Hadjigeorgiou 2019; Hadjigeorgiou \& Stacey 2017; Wagner 2011). In general, the available suite of small-scale laboratory-based specification tests are well defined in terms of specimen geometry, loading conditions and test procedures for steel, shotcrete and polymeric materials. However, for the case of large-scale performance testing, few if any examples exist of standardised test procedures, rig or in situ test configurations for support elements, loading mechanisms and failure types. As an example, a review of the available performance test rigs for mesh testing found significant variations in the size of the testing frame, bolting pattern, applied bolt tension, loading mechanism (punch or pull), loading rate, boundary conditions, bearing plate loads, size and shape of the loading device (Figure 4), mesh sizes and shape and edge conditions. These variations obviously make it difficult, if not impossible, to interpret and compare the results, whether or not they are intended to evaluate the same type of support element or loading or failure mechanism. Furthermore, for the most part, performance tests generally use 
uniaxial loading conditions; this is despite the commonly observed fact that uniaxial support situations are the exception rather than the rule (Wagner 2011).
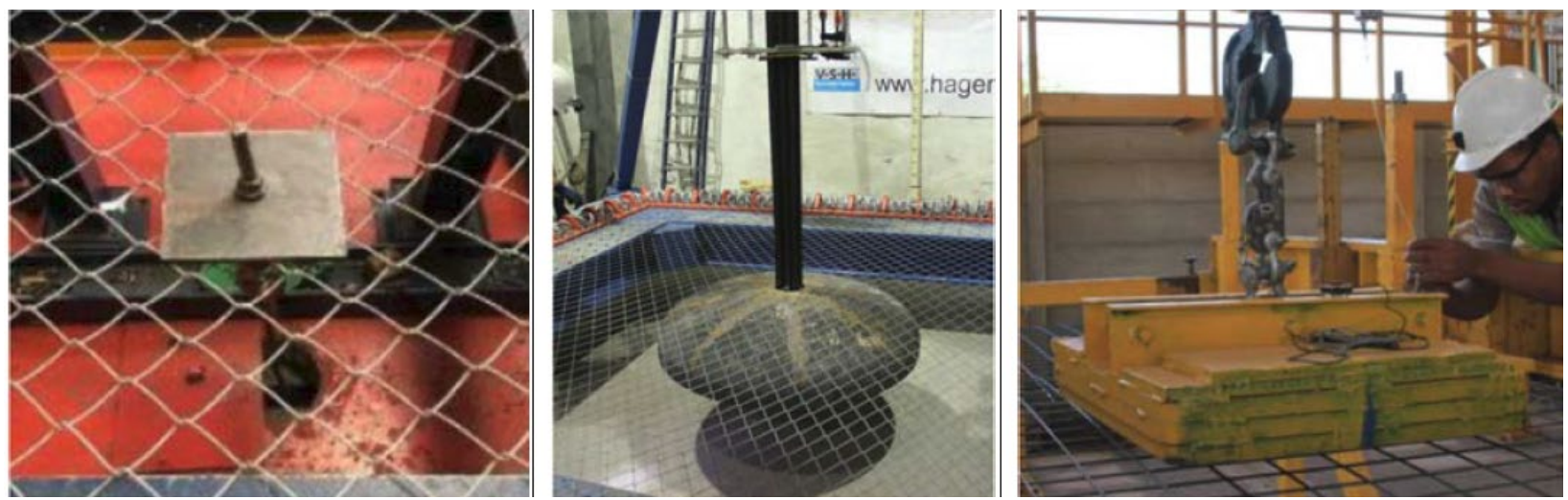

Figure 4 Examples of differences in size and shape of the devices used to load mesh in performance testing (Hadjigeorgiou \& Stacey 2017)

Faced with the above conclusions, the following recommendations have been made with respect to addressing the inconsistencies in current performance testing of bolts, mesh and even TSLs:

- Concerning laboratory-based rigs, a standardised method and testing procedure needs to be developed for both static and dynamic loading of bolts and mesh of any type. As pointed out by Hadjigeorgiou \& Stacey (2017), a rational testing procedure would require a consensus to specify the test objectives, loading mechanism, dimensions, instrumentation and method whereby results are interpreted. They further suggest that a proof of concept before adopting any proposed standard should include an exercise in numerical modelling to explore the impact and sensitivity of results to a range of set-up configurations et cetera.

- Concerning in situ type testing of support systems, in addition to all the dependent variables applicable to laboratory rigs, results are also determined by the local geo-engineering conditions-namely, the in situ stress, the rock matrix and the rock mass conditions. This only serves to increase the difficulties in making meaningful performance comparisons when it is considered that none of the common rock mass classification or rock mass rating systems are sufficiently objective to make meaningful comparisons possible (Wagner 2011). This needs to be addressed by working towards the development of a rock support prediction and design system, with which to evaluate and interpret in situ test results.

\section{$4 \quad$ Ground support equipment: capability and productivity}

From the beginning of the MIGS consortium, the capability and performance of ground support equipment-relating as it does to the effectiveness of bolt and liner installation functionality with respect to quality control and safety-has been seen as integral to the consortium's mandate. At the same time, issues around bolting productivity have been explored in some depth, beginning with a work package that sought to establish reasons to support the possible development of multi-function equipment packages (Sundqvist 2010). This was followed by an in-depth study that sought to compare the procedures and productivities of fully mechanised bolting rigs with those of manual bolting rigs for a variety of bolt types (Gustafson et al. 2016).

\subsection{Multi-function ground support equipment}

This simulation study of multi-function ground support equipment considered the case of development headings for single or multi-face scenarios and for which the base case driving layout and process flow was taken from two Swedish mines, the latter exemplified in Figure 5. The ground support cycle comprised shotcreting followed by bolting after a certain cure time. Four hypothetical cases of multi-functioning 
equipment were considered (Table 4), for which various assumptions-as realistic as possible-had to be made concerning equipment-operating practices. Results from each simulation were compiled and compared with the base case in terms of the following parameters:

- Developed meters/month-is the set-up time better/worse?

- Equipment utilisation-how has this changed with equipment functionality?

- Travelled distance-have travel time efficiencies improved?

- Activity wait times-have these been reduced?

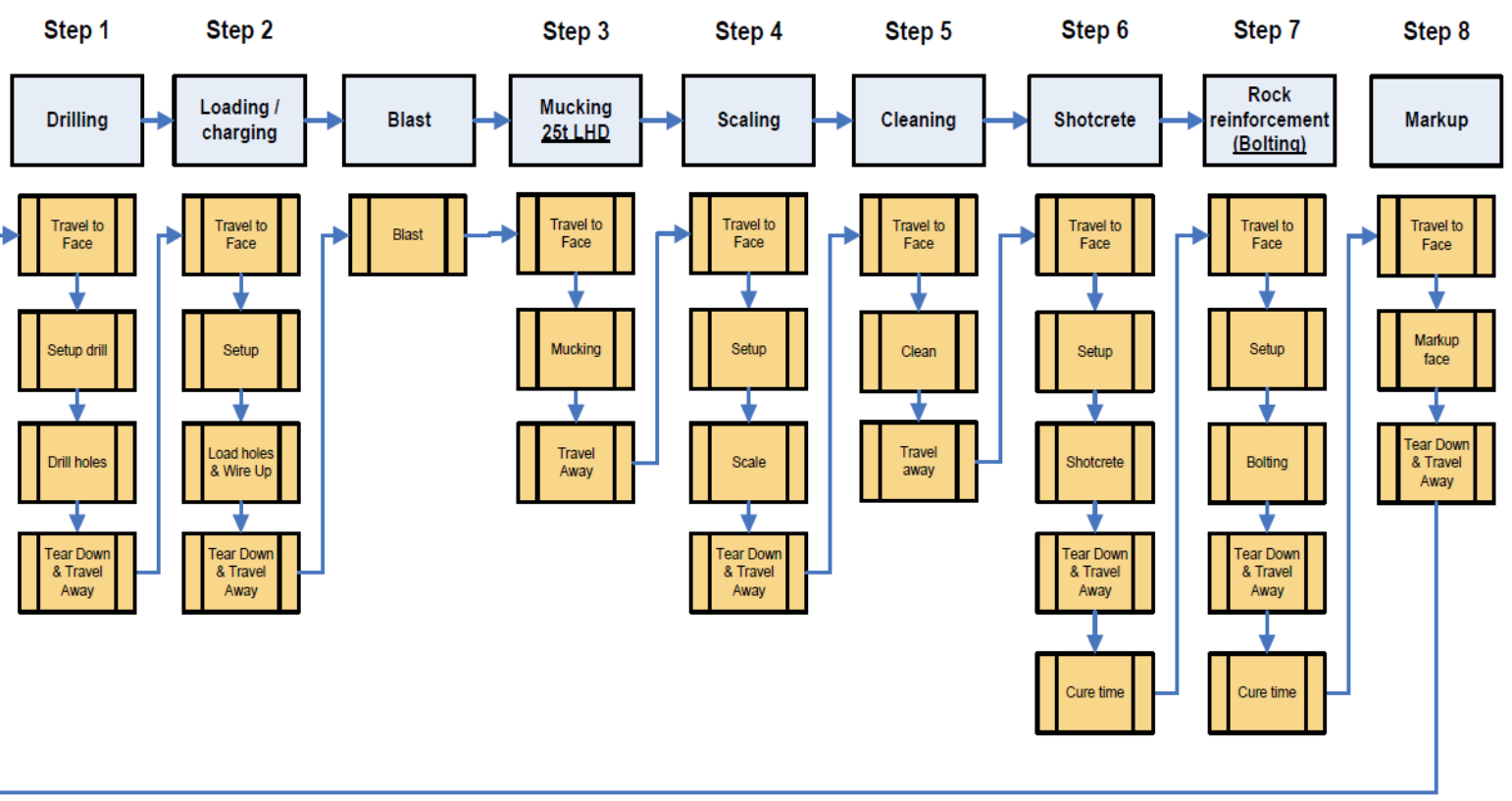

Figure 5 Base case used in simulation for excavation cycle process flow (Sundqvist 2010)

While all conclusions from this study clearly depend upon the performance assumptions of the hypothetical equipment, it is clear overall that for the assumed types of multi-function rigs, they were most productive in a single face setting and when performing in-sequence cycle activities (e.g. scaling/shotcreting/bolting). However, in all cases where a multi-function rig was simulated, if a bottleneck occurred for whatever reason, the base case performed better. Finally, if multi-functioning rigs are used, they should replace equipment with low utilisation.

Table 4 Four hypothetical multi-functioning ground support equipment cases used in a simulation study (Sundqvist 2010)

\begin{tabular}{llll}
\hline Waterscaler/shotcreter & $\begin{array}{l}\text { Waterscaler/ } \\
\text { shotcreter/bolter }\end{array}$ & $\begin{array}{l}\text { Drill rig/charger/bolt } \\
\text { driller }\end{array}$ & Drill rig/charger/bolter \\
\hline $\begin{array}{l}\text { Waterscaling } \\
\text { equipment }\end{array}$ & $\begin{array}{l}\text { Waterscaling } \\
\text { equipment }\end{array}$ & Data jumbo & Data jumbo \\
Shotcrete equipment & $\begin{array}{l}\text { Shotcrete equipment } \\
\text { Drill and bolt carousel }\end{array}$ & $\begin{array}{l}\text { Boom basket } \\
\text { Bolt drilling capability }\end{array}$ & Boolting capability \\
\hline
\end{tabular}




\subsection{Ground support equipment productivity}

This multiphase work package had three objectives:

1. To quantify current productivity limitations of bolting and screening ground support practices used in hard rock mining.

2. To identify ground support procedures and equipment that can provide real productivity improvements.

3. To suggest the way forward for increasing productivity regarding improvements to equipment, design and procedures.

Phase 1 used a prepared questionnaire to collect existing process/equipment information and time study data from mining companies, equipment suppliers and academic institutions, as well as from published literature describing the bolting and screening cycle in hard rock mines. A follow-up benchmarking study was then conducted with the MIGS membership mines on bolting and screening productivity. This study focused on the most commonly used ground support elements and the different levels of mechanisation. Phase 2, which was conducted in a workshop setting, took the findings of the benchmark study to come up with ideas on how equipment can be made more effective. This assumed the use of the rock support components in use in mines today or whether other existing components could be implemented to increase ground support cycle productivity. Some of the questions considered were:

- New ideas regarding rock support productivity at mine sites.

- New ideas regarding rock support productivity at equipment suppliers.

- Can the number of different ground support components be limited?

- What process changes could be done to increase productivity?

Out of this exercise, it became apparent that quantifying 'productivity' in a structured and relevant way operationally is not obvious. A suggested classification of the unit times associated with the process of bolting is shown in Figure 6, from which the terms 'long-term utilisation' and 'operational capacity' should be consistently determined.

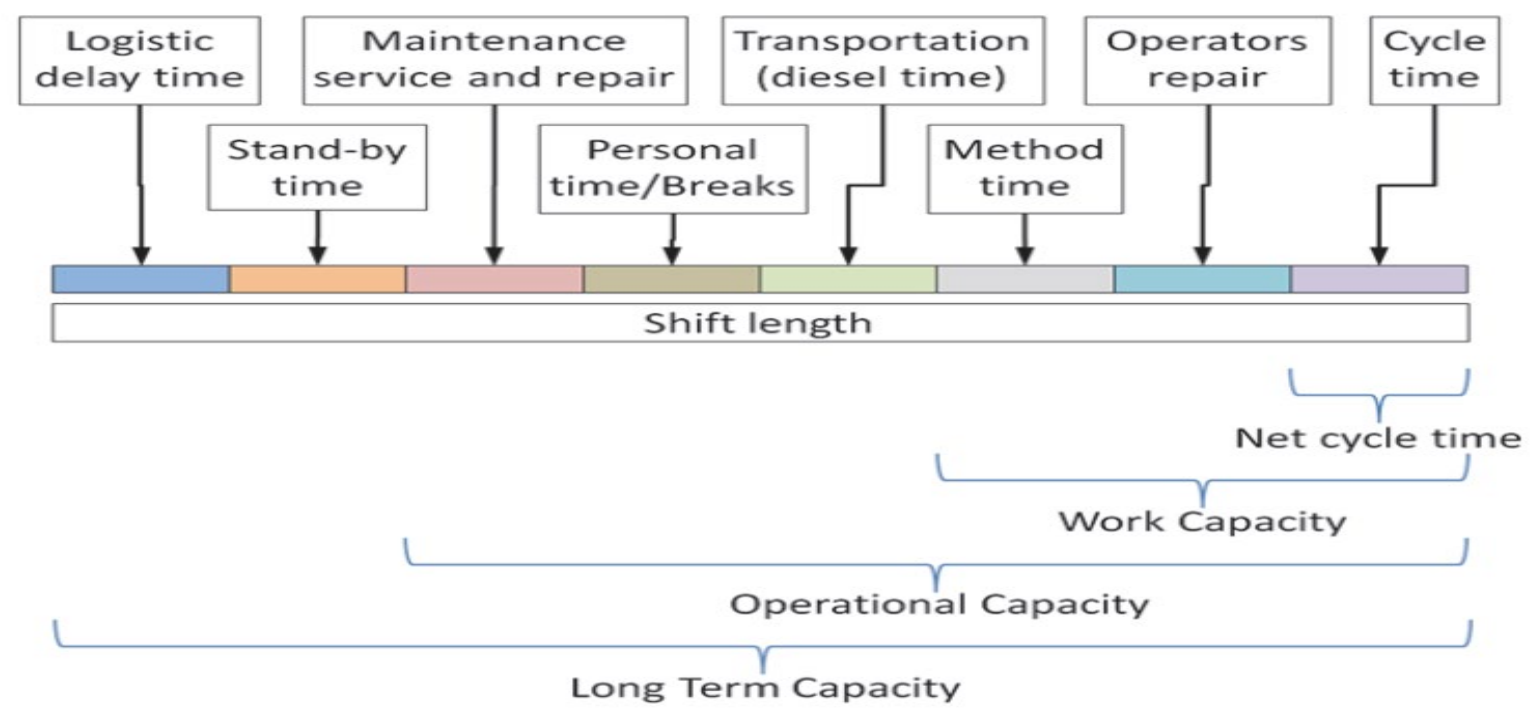

Figure 6 Suggested classifications of the unit times for rock reinforcement (Schunnesson 2014)

Also, the reasoning behind the decision by some mines to use fully mechanised bolting versus manual bolting rigs was not obvious and received considerable attention. The argument in favour of each has been expressed with equal conviction, yet it is rare to see an objectively posed comparison, as reported in this work package (Schunnesson 2014). 


\section{Ground support monitoring: towards a big data capability}

There is a general belief, rightly or wrongly, that over the life of a mine, the effectiveness and patterns of installed ground support systems could be optimised if unit load/deformation data ever became available in some continuous fashion. Certainly, this has been done in discrete sections of mines as part of a research project but never routinely on a mine-wide scale and for the life of the mine. This aspiration set the objectives for a number of work packages to find and evaluate a large data-gathering capability around ground support design and monitoring.

\subsection{Survey of current bolt-monitoring techniques}

In 2009, a SOTA study investigated available technology with the potential capability of monitoring the response of ground support elements/systems to mining on a large scale (Delsing 2009). At that time, the general characteristics of such a capability were stated as the need to be robust, reliable, automatic and wireless. While this study did identify certain well-established methods of monitoring loads, nothing qualified as fulfilling the scale, practicality and cost necessary to expect mines to adopt it as routine and integral with every bolt installed.

\subsection{Search for most desirable bolt-monitoring capability}

Taking a more direct approach to the challenge of finding a suitable bolt-monitoring capability, information gathered from mining operations on the most desirable characteristics was used in preparing a request for proposal (RFP) document. This was first distributed to known suppliers of geotechnical monitoring devices, but no suitable solutions were found. Next, the RFP document was recast in the form of a 'challenge' for the purpose of its distribution to InnoCentive Inc., an international organisation with connections to a crowd of so-called problem solvers. This document described the problem in terms shown in Table 5. Again, after working through more than 60 idea proposals, some ingenious, it was decided that none met the 'must have' cost and practicality criteria that were considered applicable to a mining application.

Table 5 Truth table of tendon status based upon observations made from the measurement of active tendon length $L$, tendon plate load $P$, and tendon plate displacement $D$

\begin{tabular}{llll}
\hline $\begin{array}{l}\text { Characteristic } \\
\text { observation }\end{array}$ & \multicolumn{3}{c}{ Measured quantity } \\
\cline { 2 - 4 } $\begin{array}{l}\text { No change in base } \\
\text { value }\end{array}$ & $\begin{array}{l}\text { Poor installation or anchor } \\
\text { plough only or no rock } \\
\text { deformation }\end{array}$ & $\begin{array}{l}\text { Poor installation or no } \\
\text { rock deformation }\end{array}$ & $\begin{array}{l}\text { No rock deformation acting } \\
\text { on tendon }\end{array}$ \\
\hline Increase in value & $\begin{array}{l}\text { Tendon functioning and/or } \\
\text { anchor stuck }\end{array}$ & $\begin{array}{l}\text { Tendon functioning } \\
\text { and/or anchor stuck }\end{array}$ & $\begin{array}{l}\text { Tendon broken or rock } \\
\text { deformation acting on } \\
\text { tendon }\end{array}$ \\
\hline Decrease in value & $\begin{array}{l}\text { Loss of plate load due to } \\
\text { collar rock fall-out or } \\
\text { suspect broken tendon }\end{array}$ & $\begin{array}{l}\text { Collar rock fall-out or } \\
\text { suspect anchor slip or } \\
\text { broken tendon }\end{array}$ & $\begin{array}{l}\text { Elastic recovery of tendon } \\
\text { due to collar rock fall-out: } \\
\text { possible ineffective tendon }\end{array}$ \\
\hline $\begin{array}{l}\text { Approaching } \\
\text { limiting design } \\
\text { value }\end{array}$ & $\begin{array}{l}\text { Tendon at capacity and } \\
\text { requires replacement }\end{array}$ & $\begin{array}{l}\text { Tendon at capacity or } \\
\text { still functional }\end{array}$ & $\begin{array}{l}\text { Rehab of excavation } \\
\text { required }\end{array}$ \\
\hline
\end{tabular}

NOTE: The status colours in Table 5 indicate different levels of concern: green = none; orange = tendon likely functioning, but follow-up recommended; red = tendon likely ineffective, but follow-up necessary. 


\subsection{Laser-scanning technology}

Taking an indirect approach to obtain bolt-monitoring data, a mobile laser-scanning trial was arranged at LKAB's Kiirunavaara mine in a bid to establish whether this evolving technology currently has the accuracy and data-processing capability to readily detect and discriminate bolt plate movements at the surface of an excavation. The trial's objective, as a minimum, was to determine whether the repeatable measuring accuracy of this technology could better $2 \mathrm{~mm}$, given a $1 \mathrm{~km}$ survey loop and a driving speed of $2 \mathrm{~m} / \mathrm{s}$. At conclusion of the trial, it was agreed that although the system is capable of observing every bolt head and measuring their respective positions and changes to their positions (Figure 7), it appears that repeatability and accuracy are still limited by certain hardware issues (Hunter et al. 2014).

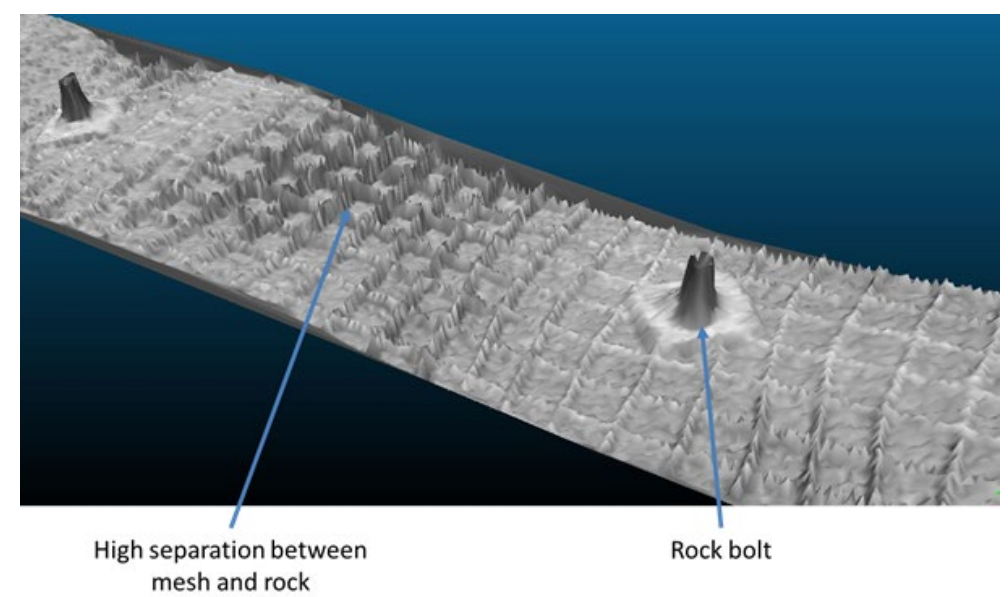

Figure 7 Laser-scanning detail taken from a $1 \mathrm{~km}$ loop trial at LKAB's Kiirunavaara mine, showing wall bolts and mesh in sufficient detail to show installation defects and bolt plate buckling as a load indicator (Hunter et al. 2014)

\section{Corrosion of ground support}

Several studies have been completed on the corrosion of ground support used in the mining industry, as follows:

- A literature survey identified recent publications referring to corrosion in mining, including a SOTA study on relevant standards and testing methods available. Most importantly, it provided qualified comments regarding the value and objectivity of work reported in the literature (Akid 2015).

- A multiphased study began with the identification of key corrosion drivers and continued on to a well-directed sample-taking program from mine sites prone to corrosion, followed by an evaluation of these sample data with which to formulate a set of preliminary recommendations of site-specific mitigation strategies. The study concluded with a proposed methodology for the execution of a corrosion risk assessment procedure together with an appropriate set of laboratory-based tests. A written guideline will then be produced covering the various topics and outcomes from the study.

\subsection{Corrosion in mining literature survey}

An extensive literature search by an independent authority suggested that relatively little has been reported on the effects of corrosion on ground support components used in the mining industry (Akid 2015). Of the literature found, the majority of studies were conducted under laboratory conditions under simulated mine environments. While this is acknowledged as being understandable, invariably the discussion of results does not include how the environmental variables, such as temperature and wet-dry cycles, may lead to differences in comparing laboratory expectations with in situ realities. The study 
concluded with a survey of the main corrosion mechanisms that may lead to component failure in a mine environment (Figure 8) and included a discussion of factors affecting the corrosion rate.

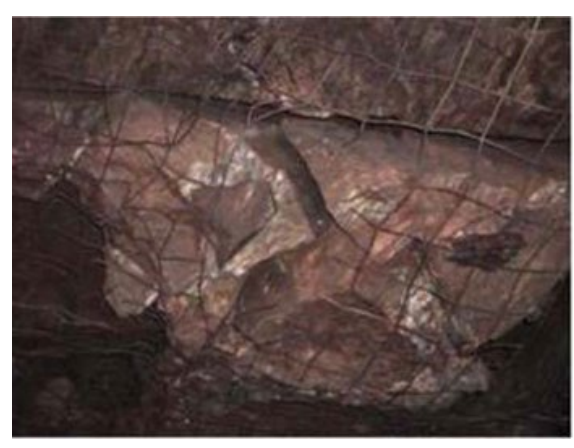

(a)

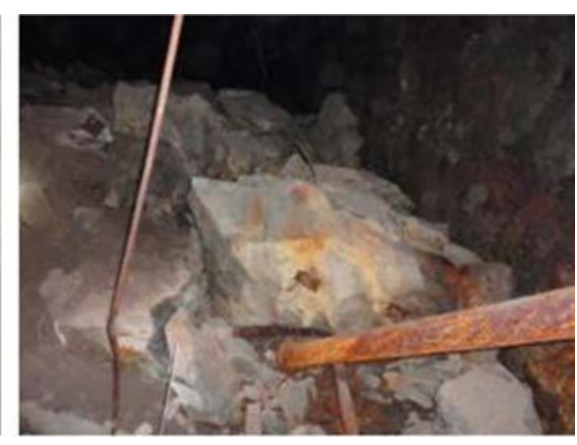

(b)

Figure 8 (a) Mesh failures; (b) A fall of ground attributed to corrosion of ground support (Dorion \& Hadjigeorgiou 2014)

\subsection{Multiphased corrosion study}

A follow-up to the literature study, this multiphased project began by producing a detailed description of the key factors in a mine environment that serve to inhibit or promote corrosion in ground support components (Feichter 2016a). It included a questionnaire and guideline for the direction of rock and water sample taking, collection and storage at participating mine sites (Figure 9, based upon Dorion \& Hadjigeorgiou 2014), which would follow under Phase 2 of the project (Feichter 2016b).

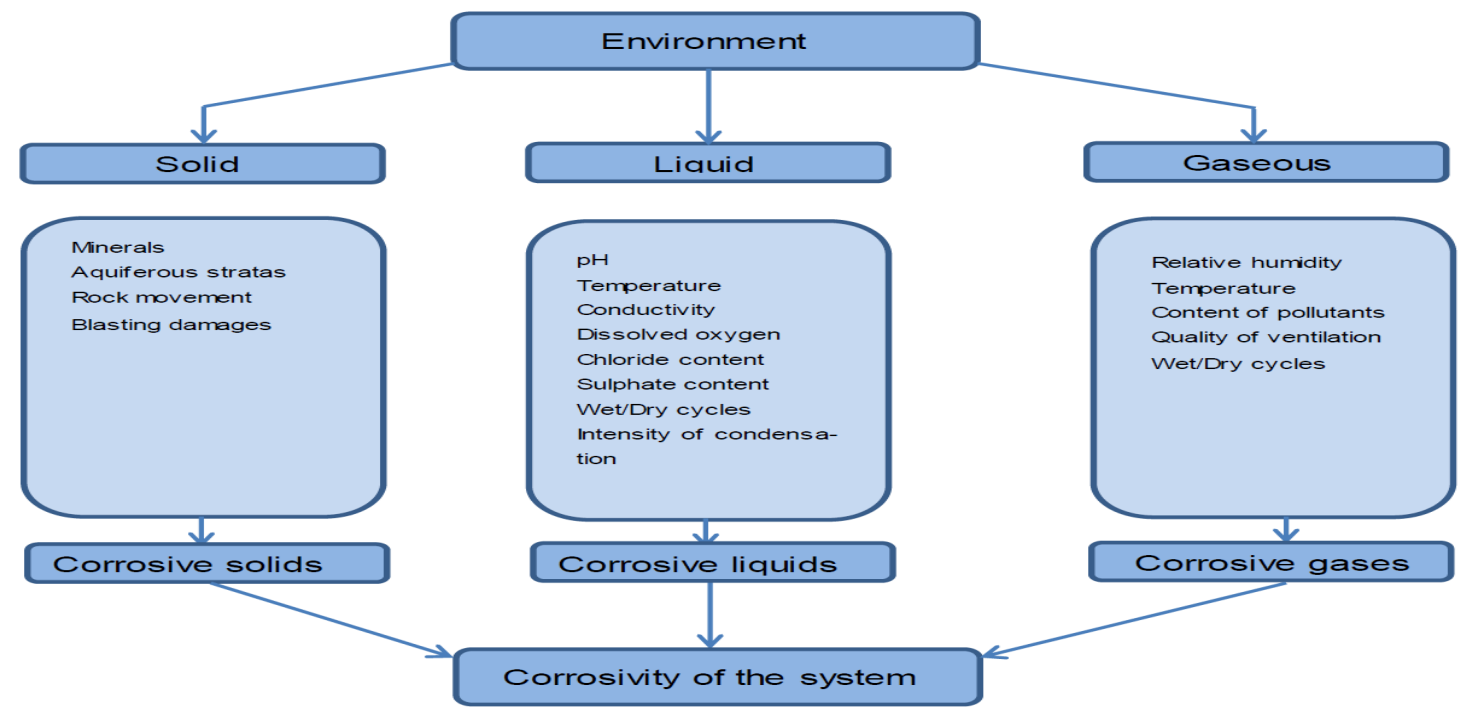

Figure 9 Schematic for data collection to assess the corrosivity of a mine, after Dorion \& Hadjigeorgiou (2014)

Phase 3 resulted in an assessment and evaluation of the corrosion samples obtained from participating mines under Phase 2 of the project. Specifically, this phase concluded by identifying the key corrosion drivers from field sample data (Deutsch \& Mori 2018), these being aerated system (always the case), low $\mathrm{pH}$ value of water and of eluate, relative humidity $(>70 \%)$ and low total hardness of water and of eluate.

Results from a limited database indicated that, of these, mine water $\mathrm{pH}$ below four is the most critical parameter resulting in severe corrosive attack, while eluate $\mathrm{pH}$ has less of an influence. High hardness and low humidity $(<70 \%)$ are both beneficial, but neither of these were found to be a sufficient prerequisite for low corrosion rates. Further work is ongoing at this time to quantify the value of the limited conclusions from Phase 3 and recommend a path forward in terms of completing the original objectives of this work package (M Hosp, pers. comm., 22 March 2019). 


\section{Conclusion}

Over the past 12 years, the Rock Tech Centre's MIGS consortium has completed 25 documented work packages comprising SOTA reviews and method/design studies on the topic of mining ground support and installation equipment. The collective output-consisting of reports, seminars and workshops-has served to demonstrate an effective measure of success in meeting the consortium's goals of pursuing and delivering short-term collective and non-competitive technical and operational benefits to its sponsors.

\section{Acknowledgement}

The authors acknowledge the financial support of the Rock Tech Centre's MIGS consortium, together with the technical and managerial contributions that its membership has made over 12 years to ensure the successful fulfilment of its mandate.

\section{References}

Akid, R 2015, 'Literature review: corrosion in the mining industry', MIGS I/ WP 16 Report, pp. 1-99.

Andersson, C 2012, 'Review of rockburst reporting protocols', MIGS II WP 13 Report, pp. 1-12.

Bäckblom, G 2010, 'Benchmarking study: design process and the QA of bolts from requirements to long-term function', MIGS I WP 8 Report, pp. 1-75.

Delsing, J 2009, 'Review of sensor technology for bolt load measurements', in MIGS I WP 3 Report, pp. 1-18.

Deutsch, J \& Mori, G 2018, 'Evaluation of field data from Phase II and key drivers for corrosion', MIGS III WP 17 Report, pp. 1-19.

Dorion, JF \& Hadjigeorgiou, J 2014, 'Corrosion consideration in design and operation of rock support systems', Mining Technology, vol. 123 , no. 2, pp. 59-68.

Feichter, M 2016a, 'Key parameters regarding corrosion in mining and tunneling', MIGS III WP 17 Report, pp. 1-40.

Feichter, M 2016b, 'Mine data collection for corrosion risk assessment', MIGS III WP 17 Report, pp. 1-9.

Gustafson, A, Schunnesson, H, Timusk, M \& Hauta, R 2016, 'Productivity of rock reinforcement: methodology development', Journal South African Institute Mining \& Metallurgy, vol. 116, pp. 1127-1134.

Hadjigeorgiou, J 2015, 'State-of-the-art, ground support systems and elements', MIGS II WP 14 Report, pp. 1-27.

Hadjigeorgiou, J 2019, 'State-of-the-art, impact (dynamic) testing of ground support', MIGS III WP 25 Report, pp. 1-14.

Hadjigeorgiou, J \& Stacey, D 2017, 'SOTA on mesh testing and capacity specification', MIGS III WP 19 Report, pp. 1-41.

Heal, D, Potvin, Y \& Hudyma, M 2006, 'Evaluating rockburst damage potential in underground mining', in DP Yale (ed.), Proceedings of the 41st US Symposium on Rock Mechanics, American Rock Mechanics Association, Alexandria, ARMA/USRMS 06-1020.

Hedley, DGF 1992, Rockburst Handbook for Ontario Hardrock Mines, CANMET Special Report SP92-1E, CANMET, Ottawa, pp. 148-152.

Hunter, G, Rayns, I \& Williams, E 2014, '3DLaserMapping-MIGS underground trial March 2014', MIGS II WP 12 Report, pp. 1-12.

$\mathrm{Li}, \mathrm{CC} 2008$, 'State of the art of ductile ground support systems and elements', MIGS I WP 2 Report, pp. 1-98.

Mikula, PA 2012a, Information on Regulatory Reporting Protocols Used in Western Australia, unpublished communication, p. 1.

Mikula, PA 2012b, Progress with Empirical Performance Charting for Confident Selection of Ground Support in Seismic Conditions, unpublished communication, p. 12.

Morissette, P, Hadjigeorgiou, J \& Thibodeau, D 2011, 'Assessment of support performance under dynamic loads at Vale Creighton Mine', Proceedings of the 45th US Rock Mechanics/Geomechanics Symposium, American Rock Mechanics Association, Alexandria, paper ARMA 11-288.

Schunnesson, H 2014 'Rock support equipment productivity', in MIGS II WP 11 Report, p.21.

Stille, H, Holmberg, M \& Stille, B 2009, 'Ductile surface support-conceptual design', in MIGS I WP 4 Report, pp. 1-34.

Sundqvist, F 2010, 'Simulation of multi-function ground support equipment using realistic production conditions from the Kiruna and Boliden mines', in MIGS I WP 7 Report, pp. 1-46.

Swan, G 2012, 'MIGS II WP 13 rockburst case histories: lessons learned summary', MIGS II Workshop, London, October, pp. 1-2.

Swan, G \& Hadjigeorgiou, J 2010, 'A critical review of thin spray-on liners (TSLs)', MIGS II WP 9 Report, pp. 1-62.

Utsi, S, Jonason, JE \& Elfgren, L 2009, 'Ductile shotcrete: a literature review', MIGS I WP 4 Report, pp. 1-64.

Wagner, H 1982, 'Support requirements for rockburst conditions', in NC Gay \& EH Wainwright (eds), Proceedings of the 1st International Congress on Rockburst and Seismicity in Mines, The Southern African Institute of Mining and Metallurgy, Johannesburg, pp. 209-218.

Wagner, H 2011, 'Overview of test methods for ground support', MIGS I WP 5 Report, pp.1-91.

Zhang, P 2019, 'Dynamic support model: discussion of design guideline document', MIGS III WP 21 Status Report, pp. 1-38.

Zhang, P, Swan, G \& Nordlund, E 2015, '1D numerical simulation of velocity amplification of P-waves travelling through fractured rock near a free surface', The Journal of The Southern African Institute of Mining and Metallurgy, vol. 115, no. 11, pp. 1121-1126. 